\title{
Nasal Polyposis: An Experience in Mid and Far Western Region of Nepal
}

\author{
Sharma $A^{1}$, Saxena $R K^{2}$, Verma $L R^{3}$
}

\begin{abstract}
Background: Nasal polyposis is an unpleasant disease in the developing countries which severely interferes with quality of life but still there is a lack of data on nasal polyposis in Mid and Far Western Region of Nepal. Aim of study: The aim of this hospital based study was to find out the distribution, patterns, presentations and management of nasal polyposis in Mid and Far Western Region of Nepal with a view to improve our understanding of its clinical and epidemiological characteristics. Methods: This prospective descriptive study was conducted from January 2015 to June 2016 in 80 patients diagnosed clinically as nasal polyposis, in the department of otorhinoloryngology, Nepalgunj Medical College Teaching Hospital, Kohalpur. Results: The most common age group affected in the study was comparatively younger ranging from 10-20 yrs. Ethmoidal Polyp were more frequent than antrochoanal polyp (56.25\% vs $43.75 \%$ ). Antrochoanal polyp were more common among the younger age groups $10-20$ yrs (30\%) where as the ethmoidal polyp were more common among higher age group. All antrochonal polyps (100\%) were unilateral while majority of the ethmoidal polyps (89\%) were bilateral. The main presenting clinical features were nasal obstruction (100\%), nasal discharge (93.75\%), sneezing (72.5\%) and headache (40\%). Conclusion: Nasal polyposis is common in Mid and Far western region of Nepal. Ethmoidal polyps are more common than antrochoanal polyps and are usually bilateral. Antrochoanal polyps are unilateral and mostly present in 10-20yrs age group patients. Patients usually present late when the polyps are large.
\end{abstract}

Key words: Antrochoanal polyp, ethmoidal polyp, nasal polyposis, Nepal.

\section{INTRODUCTION}

Nasal polyposis are outgrowths of nasal mucosa which are smooth, semi translucent, gelatinous and pale mass present in the nasal cavity, mainly situated in the middle meatus, originating from mucous membrane of the ostiomeatal complex, probably because of release of pro inflammatory cytokines from epithelial cells as a result of contact between two surfaces of mucosa at this narrow region. Nasal polyposis despite its easy diagnosis, is a challenge for otorhinolaryngologist because of its poorly understood etiopathogenesis, poor impact of therapeutic intervention and frequent recurrences. It is a multifactorial condition which is often associated with many diseases and pathogenic disorders, such as allergy, infection, allergic fungal sinusitis, cystic fibrosis, asthma, and aspirin intolerance ${ }^{1}$.

The incidence of nasal polyposis (NP) is around $4 \%$ in the general population ${ }^{2}$. Adults are predominantly affected, usually patients older than $20 \mathrm{yrs}$, and are uncommon in children under 10 yrs. Male are commonly affected with $M$ : F ratio of $2: 1^{3}$. Therapy for NP involves a combination of observation, medical,

1. Dr. Anshu Sharma

2. Prof. R. K. Saxena

3. Dr. Lok Ram Verma

Address for correspondence:

Dr. Anshu Sharma

Department of ENT

Nepalgunj Medical College \& Teaching Hospital

Nepalgunj, Banke, Nepal

Email: anshusa.regmi@gmail.com and surgical treatments depending on individual case assessment. The aims of treatment are to eliminate or significantly reduce the size of the NP resulting in relief of nasal obstruction, improvement in sinus drainage, restoration of olfaction and taste. In addition to surgical treatment supplementary medical treatment is always necessary to prevent recurrence ${ }^{4}$.

\section{MATERIAL AND METHOD}

This was a prospective descriptive study, conducted from January 2015 to June 2016 in the department of otorhinoloryngology, Nepalgunj Medical College Teaching Hospital, Kohalpur. Among the 21,250 cases presented in our OPD during this period 80 patients were diagnosed clinically and via nasal endoscopy as nasal polyposis and were taken as study group. When required imaging studies were done. Demographic Profile of the patient and clinical presentation of the disease were assessed. Endoscopic grading of polyp was done with system proposed by Johansen et al, $1993^{5}$. Classification of polyp according to the site was done and their occurrence in different age groups were compared.

All the patients with Johansen Score 2 or more who didn't respond to medical therapy underwent surgery either endoscopic polypectomy or fuctional endoscopic sinus surgery (FESS). Histopathological examination was done in all cases.

\section{RESULTS}

Demographic Profile: Total patients in the OPD were 21,250 among whom 80 patients were diagnosed as nasal polyposis. The incidence of the disease thus calculated was 376/100,000. 
The mean age of the patient was 36.03 yrs. with the minimum and maximum age of 8 and 68 yrs. respectively. The most common age group affected in the study was comparatively younger ranging from 10-20 yrs. figure 1 . The present study shows male preponderance, Male: Female $=46$ (57.5\%): 34 (42.5\%).

Type of polyp: Antrochoanal polyp were more common among the younger age groups $10-20$ yrs. $24(30 \%)$ where as the ethmoidal polyp are more common among thereafter.

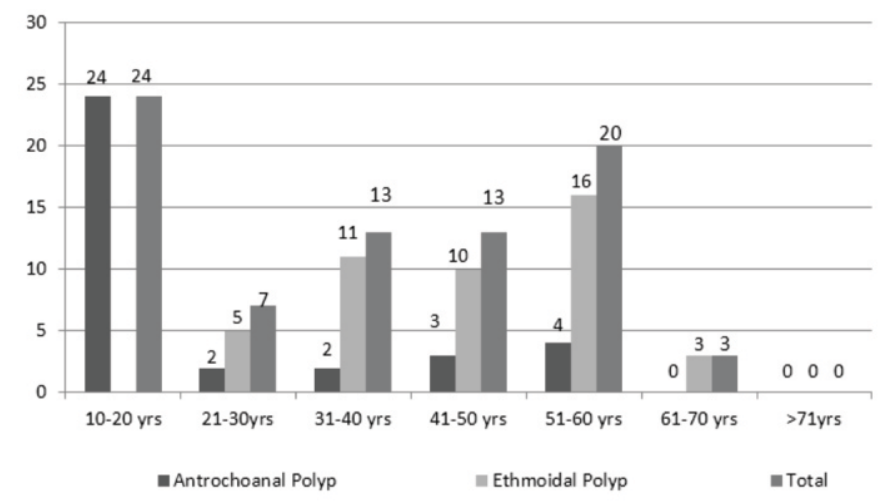

Figure 1: Correlation between the Age of patients with Type of polyp

Among the 80 cases, 35(43.75\%) were antrochoanal polyp and 45(56.25\%) ethmoidal polyp as shown in table I. All antrochonal polyps were unilateral while majority of the ethmoidal polyps were bilateral.

Clinical features: The main presenting clinical features were nasal obstruction 80(100\%), nasal discharge 75(93.75\%), sneezing 58(72.5\%) and headache 32 (40\%).

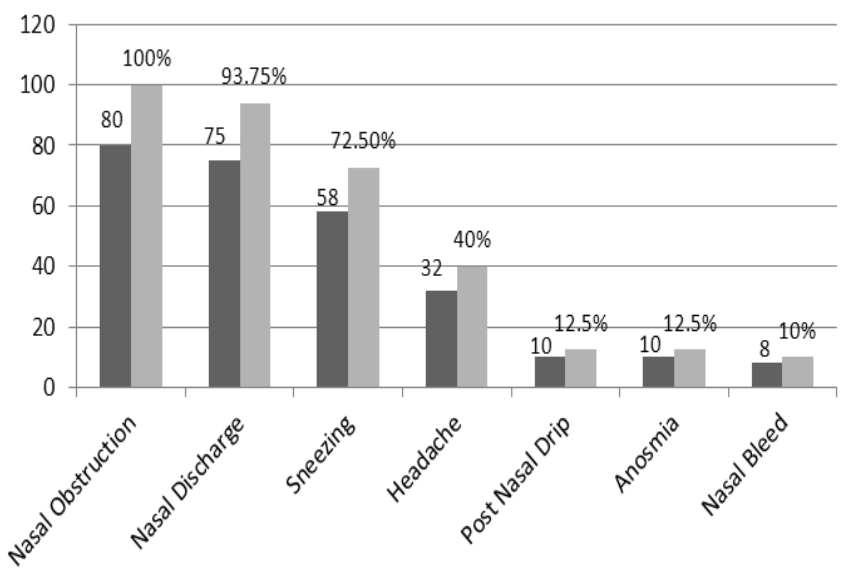

Figure 2: Distribution based on symptoms of patients
Staging Of Polyp: The size and location of polyps were confirmed by doing nasal endoscopy. Majority of the cases presented with stage 2 and 3 polyposis (Figure 3 ).

3

$(3.75 \%)$

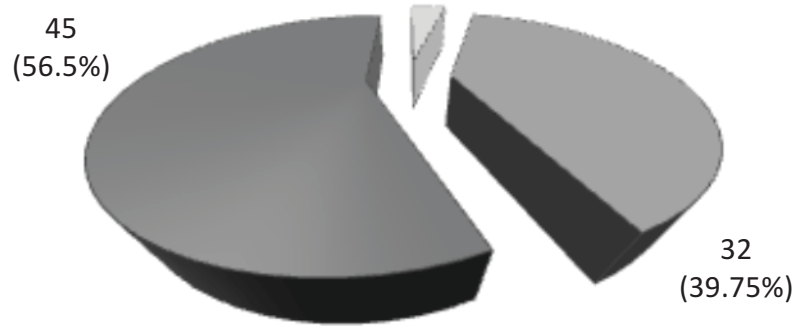

Restricted to middle meatus (Grade 1)

- Below middle turbinate (Grade 2)

Massive polyposis (Grade 3)

Figure 3: Endoscopic staging of Nasal Polyp

Histopathological examination revealed 5(6.25\%) as inverted papilloma, $8(10 \%)$ as fungal polyposis and $67(83.75 \%)$ diagnosed as nasal polyposis.

\begin{tabular}{|c|c|}
\hline Nasal Polyposis & $67(83.75 \%)$ \\
\hline Fungal Polyposis & $8(10 \%)$ \\
\hline Inverted Papilloma & $5(6.25 \%)$ \\
\hline
\end{tabular}

Table II: Histopathological Findings

\section{DISCUSSION}

Nasal polyposis is the most common intranasal mass seen in clinical practice. Its rarity in children and propensity for recurrence are reaffirmed. Although, recurrence is a major prognostic challenge, nasal polyp does not exhibit malignant transformation ${ }^{6}$.

Many proposed theories consider that nasal polyps are a consequence of conditions which cause chronic inflammation in the nose and nasal sinuses characterized by stromal edema and variable cellular infiltrate ${ }^{7}$. However, the etiology of nasal polyposis is not known clearly ${ }^{8}$. It was previously assumed that allergy is the predisposing factor for nasal polyps because the symptoms of watery rhinorrhea and mucosal swelling were

\begin{tabular}{|l|c|c|c|c|}
\hline Diagnosis & No. of Cases (\%) & Left (\%) & Right (\%) & B/L(\%) \\
\hline Antrochoanal polyp & $35(43.75 \%)$ & $19(23.75)$ & $16(20)$ & - \\
\hline Ethmoidal polyp & $45(56.25 \%)$ & $3(3.75)$ & $2(2.5)$ & $40(50)$ \\
\hline
\end{tabular}

Table I: Distribution of cases 
present in both conditions and were associated with an abundance of eosinophils in the nasal secretions ${ }^{9}$.

In our study nasal obstruction was the chief symptom present in $100 \%$ cases. It was followed by nasal discharge $93.75 \%$, sneezing $72.5 \%$ and headache in $40 \%$ cases. A similar findings were observed in a study made by O.A Ogunleye and A. J. Fasunla where the nasal obstruction, nasal discharge and sneezing in nasal polyposis were $95 \%, 81 \%$ and $59 \%$ respectively ${ }^{10}$.

Male preponderance was seen in our study ( $\mathrm{M}: \mathrm{F}=1.5: 1)$. The mean age in our study was 36 years and most of our patient had ethmoidal polyp (56.25\%). It is comparable to the study done by Hemant Chopra in 2008 where the mean age was 38.08 years ${ }^{11}$.

In the present study Antrochoanal Polyps 30\% were more common in younger age groups of $10 y$ rs-20yrs whereas ethmoidal polyps were more frequent thereafter. Affection of nasal polyposis in younger patients could be due to the fact that they are the most active and exposed to various allergens due to their outdoor activities. In our study patients of nasal polyposis in mid and far Western region of Nepal presented in the hospital when the polyp is large (Score 3:2:1= $56.25 \%: 40 \%: 3.75 \%$ ) as classified according to johansen scoring.

The diagnosis of nasal polyposis is usually made on clinical grounds whereas histopathologically the findings may differ ${ }^{12}$. In a study done in Malayasia by Irfan M and Shamim AK in 2009 showed that majority of the histological reports are inflammatory nasal polyp (93.6\%) and other varieties of benign nasal mass (5.3\%). However, one specimen was noted to be malignant $(1.1 \%)^{13}$. Similarly in our study $6.25 \%$ cases turned out to be inverted papilloma on histological reports.

\section{CONCLUSION}

This study shows that nasal polyposis is common in Mid and Far Western region of Nepal and has male preponderance. This study also shows that, in this region antrochoanal polyps are more common in younger age groups of 10-20 years and are unilateral but ethmoidal polyps are more common thereafter and are mostly bilateral. Here the patients have nasal obstruction as the most common complain followed by other symptoms like nasal discharge, sneezing, headache etc. Patients present to the hospital when the polyps are large enough to pass beyond middle meatus.

\section{REFERENCES}

1. Davis LJ, Kita H.Pathogenesis of chronic rhinosinusitis: role of airborne fungi and bacteria. Immunol Allergy Clin North Am. 2004;24:59-73.

2. Hedman J, Kaprio J, Poussa T, Neiminen MM. Prevalence of asthma, aspirin intolerance, nasal polyposis and chronic obstructive pulmonary disease in a population-based study. Int J
Epidemiol. 1999;28:717-722.

3. Settipane GA. Epidemiology of nasal polyps. Allergy Asthma Proc. 1996;17: 231-36.

4. Rajguru R . Indian J Otolaryngol Head Neck Surg (2014) 66 (Suppl 1):S16-S21.

5. Johansen VL, Illum P, Kristensen S, Winther L, Petersen S, Synnerstad B.The effect of Budesonide (Rhinocort ${ }^{\circledR}$ ) in the treatment of small and medium sized nasal polyps. Clin Otolaryngol 1993; 18: 524-7.

6. Olajuyin OA, Olajide TG. Patterns, Presentations and Prognosis of Nasal Polyps. Indian Journal of Otolaryngology and Head \& Neck Surgery. Apr,2017:1-5

7. Bateman ND, Fahy C, Woolford TJ. Nasal polyps: still more questions than answers. J Laryngol Otol. 2003;117: 1-9.

8. Soltankhah MS, Majidi MR, Shabani SH. Medical treatment of nasal polyps: a review. Rev Clin Med 2. 2015;1: 24-27.

9. Settipane GA, Chafee FH. Nasal polyps in asthma and rhinitis. A review of 6037 patients. J Allergy Clin Immunol. 1977;59: 17-21.

10. Ogunleye OA and Fasunla AJ. Nasal polyps - clinical profile and management in Ibadan. Nigerian journal of surgical research Vol 7 vol 1-2,2005: $164-167$

11. Chopra H. Nasal polyps: a clinical, histopathological and radiological profile.Indian J. Otolaryngol. Head Neck Surg. 2008;60:112-116. DOI 10.1007/s12070-007-0118-y

12. Garavello W, Gaini RM. Histopathology of routine nasal polypectomy specimens: a review of 2,147 cases. Laryngoscope. O c t $2005 ; 115(10): 1866-8$. D O I: 10.1097/01.mlg.0000177075.09594.90

13. Irfan M, Shamim AK. Routine histological examination for nasal polyp specimens: is it necessary? Med J, Malayasia. Mar 2009;64(1):59-60. 